\title{
CARACTERIZAÇÃO DA DINÂMICA PRODUTIVA DE GRÃOS E DA PROPRIEDADE TÍPICA REGIONAL NO SUL DO BRASIL
}

\author{
Characterization of dynamics in grain production and \\ typical farm in Southern Brazil
}

\begin{abstract}
RESUMO
O segmento agropecuário representa papel relevante para a economia do Brasil. O produtor rural detém à sua disposição diferentes possibilidades de composição do sistema produtivo, sendo que sua escolha se traduz em padrões agregados de comportamento, que definem o suprimento de alimentos de determinada região. O Sul do Brasil responde por considerável área cultivada nacional de soja, milho e trigo. Objetivou-se neste trabalho caracterizar a dinâmica produtiva dos cultivos de grãos e da propriedade típica regional no Sul do Brasil. Utilizou-se fontes de dados secundárias sobre oferta, demanda e área semeada, e sobre a propriedade típica regional coletada via técnica painel, disponibilizada pelo CEPEA/CNA, para Cascavel/PR, Londrina/PR, Castro/PR, Guarapuava/PR, Carazinho/RS e Tupanciretã/RS, compreendendo as safras de 2012/13 a 2018/19, e para Campos Novos/SC, Xanxerê/SC de 2013/14 a 2018/19. Conclui-se que a soja tem representado elevada proporção de cultivo na primeira safra, seguido por milho e feijão primeiras safras. Para a segunda safra, há cultivo predominante de milho segunda safra em Cascavel/PR e Londrina/PR, e elevada proporção de cobertura verde nas demais regiões, sendo o trigo cultivado em menor intensidade. Futuros estudos são necessários para quantificar a superioridade da cultura da soja em termos econômicos, dada sua crescente participação nas propriedades típicas no Sul do Brasil. Ainda, deve-se compreender a preferência pela adoção de cobertura verde na segunda safra, em detrimento do trigo, pois não é comercializada e não gera receita. Este trabalho contribuiu para identificar tendências do cultivo de grãos no Sul do Brasil, e fornecer questões para futuras pesquisas.
\end{abstract}

Gabriel Diniz Faleiros

Escola Superior de Agricultura Luiz de Queiroz

gdfaleiros@gmail.com

Lucilio Rogerio Aparecido Alves

Escola Superior de Agricultura Luiz de Queiroz

Iralves@usp.br

Recebido em: 05/02/2020. Aprovado em: 23/03/2021.

Avaliado pelo sistema double blind review

Avaliador científico: Elisa Reis Guimarães

DOI: $10.48142 / 2220201554$

\begin{abstract}
The agricultural sector plays an important role in the Brazilian economy. The rural producer has at his disposal different possibilities of composition of the productive system, and his choice translates into aggregate patterns of behavior, defining regional food supply. Southern Brazil accounts for a considerable national acreage of soy, corn and wheat. The objective of this work was to characterize the productive dynamics of grain crops and typical regional property in Southern Brazil. Secondary data sources were used on supply, demand and sown area, and on the typical regional property collected via panel technique, made available by CEPEA/ CNA, for Cascavel/PR, Londrina/PR, Castro/PR, Guarapuava/PR, Carazinho/RS and Tupanciretã/RS, comprising the 2012/13 to 2018/19 seasons, and for Campos Novos/SC, Xanxerê/SC from 2013/14 to 2018/19. It is concluded that soybeans have represented higher proportion of cultivation as the first crop, followed by corn and beans first crops. For the second crop, there is a predominant cultivation of second crop corn in Cascavel/PR and Londrina/PR, and a high proportion of cover crop in the other regions, with wheat being cultivated at a lower intensity. Future studies are needed to quantify the superiority of soybean in economic terms, given its growing participation in typical properties in Southern Brazil. Still, one must understand the preference for the adoption of cover crop in the second crop, instead of wheat, as is not sold and does not generate revenue. This work contributed to identify grain cultivation trends in Southern Brazil and provided questions for future research.
\end{abstract}

Palavras-chave: Sistema produtivo; oferta e demanda; soja; milho; trigo.

Keywords: Productive system; supply and demand; soybean; corn; wheat.

\section{INTRODUÇÃO}

O segmento agropecuário representa papel relevante para a economia do Brasil, e detém características singulares em seu modo de produção (KAY; EDWARDS;
DUFFY, 2014). O setor pode se mostrar estratégico para determinada nação, seja pelo fornecimento de alimentos à sua população, seja pela expressiva participação no produto interno bruto do país. 
Partindo de uma perspectiva de caráter micro, as ações de agricultores se traduzem em padrões agregados de comportamento, que definem o suprimento de alimentos de determinada região, com destino final o consumo humano ou animal, nos mercados interno ou externo. Considerase que o produtor rural detém à sua disposição diferentes possibilidades de composição do sistema produtivo, sendo que sua escolha reflete a conjuntura econômica, política e financeira, bem como as relações entre os diversos agentes da cadeia agroindustrial.

Os estados do Paraná, de Santa Catarina e do Rio Grande do Sul respondem, juntos, por aproximadamente um terço da produção total de soja do Brasil, $40 \%$ de milho primeira safra, e $85 \%$ de trigo CONAB (2021b). Outras culturas menos representativas também são cultivadas, notadamente feijão de primeira e segunda safras, cevada e aveia branca (CEPEA/CNA, 2019).

Soja, milho e trigo, são, portanto, as principais culturas temporárias do Sul do Brasil. Em anos recentes, observaram-se incrementos expressivos de cultivo de soja em primeira safra, em detrimento do cultivo de milho na primeira safra (CONAB, 2021b). Ao mesmo tempo, houve uma intensificação do cultivo de milho em segunda safra, especialmente após a colheita de soja. Porém, o trigo, importante cultura de inverno e que concorre com o cultivo de milho de segunda safra em algumas regiões, apresentou alterações de áreas ao longo dos anos, apesar de o Brasil ser um dos maiores importadores mundiais de trigo (CONAB, 2021b). Outro ponto de destaque, é que há cultivos de culturas não comerciais, denominadas de cobertura verde, no Sul do Brasil, as quais ocupam consideráveis proporções de área cultivada em segunda safra (CEPEA/CNA, 2019).

Em virtude do exposto, o objetivo deste trabalho é caracterizar a dinâmica produtiva dos cultivos de grãos e da propriedade típica regional no Sul do Brasil. Assim, será possível compreender as inter-relações entre as culturas temporárias adotadas em regiões selecionadas e no Sul do Brasil como um todo, identificando tendências e questões de pesquisa para estudos posteriores. Serão utilizadas fontes de dados secundárias sobre oferta e demanda, e sobre a propriedade típica regional coletada via técnica de painel e disponibilizada pelo CEPEA/CNA (2019).

\section{REFERENCIAL TEÓRICO}

Neste tópico, explora-se a caracterização de sistema produtivo com embasamento na literatura científica, mostrando-se essencial para se atingir o objetivo proposto - entender a dinâmica produtiva do cultivo de grãos. Há uma diversidade de denominações similares entre si para designar o sistema produtivo agrícola, ao mesmo tempo em que se verifica uma ausência de consenso. Entretanto, a noção central de todas estas definições converge para o termo sistema produtivo, que consiste em uma das etapas de tomada de decisão do gestor e se baseia na definição de sequência de semeio de culturas, da tecnologia a ser adotada e da escolha e coeficientes técnicos de cada insumo utilizado.

Tanaka et al. (2002) integram os fatores internos e externos em um conceito só, denominado de Sistema de Cultivo Dinâmico (SCD), caracterizado como sustentável. O SCD foi desenvolvido com o intuito de auxiliar os administradores rurais a resolver problemas, abordando, dentre outros fatores, a otimização da sequência de possíveis culturas e seus resultados. Neste modelo, o gestor busca atingir metas específicas, considerando as várias facetas que influenciam o desempenho da propriedade rural, tais como os aspectos produtivo econômico, social e ambiental.

Outra designação correlata a sistemas produtivos é o termo sistemas agrícolas, utilizado por Jones et al. (2016). De acordo com os autores, compreende uma área de estudo interdisciplinar das ciências, a qual propõe a compreensão da dinâmica do comportamento dos sistemas agrícolas, levando em consideração a interdependência entre a produção agrícola, os recursos naturais, e o componente humano.

Têm-se na produção de um dado produto uma sequência ordenada e lógica de várias etapas interdependentes, constituídas pela entrada de um ou mais insumos e saída de produtos, realizado por métodos específicos, englobando desde a entrada da matéria-prima na primeira etapa, até a saída do último produto, ao término do processo produtivo. Assim, ocorrem transformações ao longo do tempo, visando atingir um determinado resultado ao término do processo, condizente com o planejado previamente.

Tanto a sucessão quanto a rotação de culturas devem ser consideradas na composição do sistema produtivo, realizada durante o momento de planejamento da safra, pois a escolha das culturas a serem cultivadas não se dá de maneira independente. A sucessão de culturas se refere ao cultivo de duas ou mais culturas em período inferior a um ano, isto é, há cultivo de duas safras em um único ano agrícola, de forma sequencial (EMYGDIO; ROSA; OLIVEIRA, 2017). A época de semeadura da cultura de primeira safra influencia o seu momento de colheita e, consequentemente, a época de semeadura da segunda safra, repercutindo no potencial produtivo de ambas.

Já para a rotação de culturas, considera-se o cultivo de duas ou mais culturas em período de tempo superior a um ano (EMYGDIO; ROSA; OLIVEIRA, 2017). 
Em outras palavras, tem-se o cultivo de uma sequência ordenada de culturas, numa mesma porção de terra, de maneira a alternar sua composição entre um ano e outro (BULLOCK, 1992), em contraste à monocultura, na qual cultiva-se a mesma cultura repetidamente, ano após ano, com ausência de diversidade (POWER, 1990).

O trabalho de Ibarrolas-Rivas e Nonhebel (2016) é interessante no sentido de incorporar padrões do consumo alimentar humano de produtos agropecuários, considerando dois extremos: baixo consumo de produtos de origem animal (pecuária) e alto consumo dos mesmos. Em detrimento desta dinâmica, têm-se uma demanda maior de grãos ora para alimentação animal, ora para alimentação humana, alterando toda a cadeia produtiva de determinada região.

A melhoria agronômica do sistema como um todo foi analisada por King e Hofmockel (2017), em função das práticas e técnicas adotadas. Os autores afirmam que a rotação de culturas e o manejo do solo impactam diretamente no sistema produtivo agrícola.

$\mathrm{O}$ aspecto econômico também tem sido incorporado na análise e definição de sistemas produtivos. Brum e Muller (2008) mencionam que o trigo tem sido semeado com finalidade de compor a rotação soja-trigo ou para diluir os custos fixos da propriedade, mesmo com o cenário econômico desfavorável para o trigo. Baumgratz et al. (2017) afirmam que o trigo não concorre com culturas de primeira safra, como soja e milho, além de auxiliar no pagamento parcial dos custos fixos da propriedade rural.

Além do caráter econômico, outros fatores também são analisados. Cita-se especialmente a viabilidade agronômica, a qual sofre influência das condições edafoclimáticas, e de épocas de semeadura e ciclo das cultivares, o que delimita as possíveis combinações de produção de uma região.

De acordo com Dijk et al. (2017), a integração entre a abordagem agronômica e a econômica promove uma perspicácia incremental, essencial para tratar os sistemas produtivos. A rotação ou sucessão de culturas impacta diretamente sobre a geração de caixa da propriedade, uma vez que a receita bruta é contabilizada multiplicando-se a produtividade pelo preço, observadas as mesmas unidades de medida. O sistema de produção adotado, bem como a sequência estabelecida da rotação das culturas, influencia na produtividade obtida (ST-MARTIN et al., 2017).

A diversificação do sistema produtivo promove o aumento na produtividade das culturas, contribuindo com a manutenção de altas produtividades ao longo do tempo (ST-MARTIN et al., 2017). Apesar de muitos estudos demonstrarem os efeitos da rotação de culturas e do sistema de cultivo sobre as produtividades, as diferentes composições e sequências de culturas, além das formas de preparo do solo, influenciam diferentemente as produtividades de cada cultura, como pode ser observado no estudo de Fonte et al. (2018). Desta forma, é tarefa do administrador rural experimentar diferentes práticas e técnicas em sua propriedade rural, realizando análises posteriores para identificação do manejo que vai ao encontro de seu planejamento e preferência.

\section{CARACTERIZAC̃̃O DA OFERTA, DEMANDA, E ÁREA SEMEADA PARA AS CULTURAS DA SOJA, MILHO E TRIGO NO SUL DO BRASIL}

\subsection{Balanço nacional de oferta e demanda para soja, milho e trigo em grãos}

Para soja em grão (Figura 1), os dados mostram que a produção vem aumentando ao longo do tempo, alavancando em consequência as exportações, haja vista que o consumo interno não tem aumentado em mesma proporção. Há um descolamento nítido entre a produção e o consumo, sendo que este último representou, em média, $42,0 \%$ do total produzido entre as safras 2012/13 e 2018/19, com tendência de perda da participação (CONAB, 2021a).

A safra 2012/13 representou uma inversão da relação entre consumo e exportação, no sentido de que as exportações superaram, pela primeira vez no período analisado, o consumo doméstico, aumentando gradativamente sua importância. Na década de 2010, a cada dois anos, aproximadamente, o Brasil aumentou seu patamar de exportação em 10 milhões de toneladas. As importações, por outro lado, são inexpressivas. De acordo com Oliveira (2017), o grande avanço da produção de soja nacional no século XXI resultou mais de aumentos em área semeada do que de aumento de produtividade.

Assim como a soja, a produção de milho vem aumentando ao longo do tempo (Figura 2) e chegou a atingir 97 milhões de toneladas em 2016/17 (CONAB, 2021a). Como a oferta de milho superou a demanda interna a partir da safra 2005/06, o excedente deu sustentação às exportações, que apresentaram em média 25,7 milhões de toneladas anuais entre as safras 2011/12 e 2018/19, representando 31,4\% da produção (CONAB, 2021a). Um salto nas exportações ocorreu na safra 2011/12, elevando o patamar de transações físicas no mercado externo, coincidente com um aumento da produção. A safra de 2011/12 representou um marco importante na produção de milho no Brasil, por ocasião do aumento de seu cultivo na segunda safra, que passou a ser a mais representativa na composição da oferta total. 


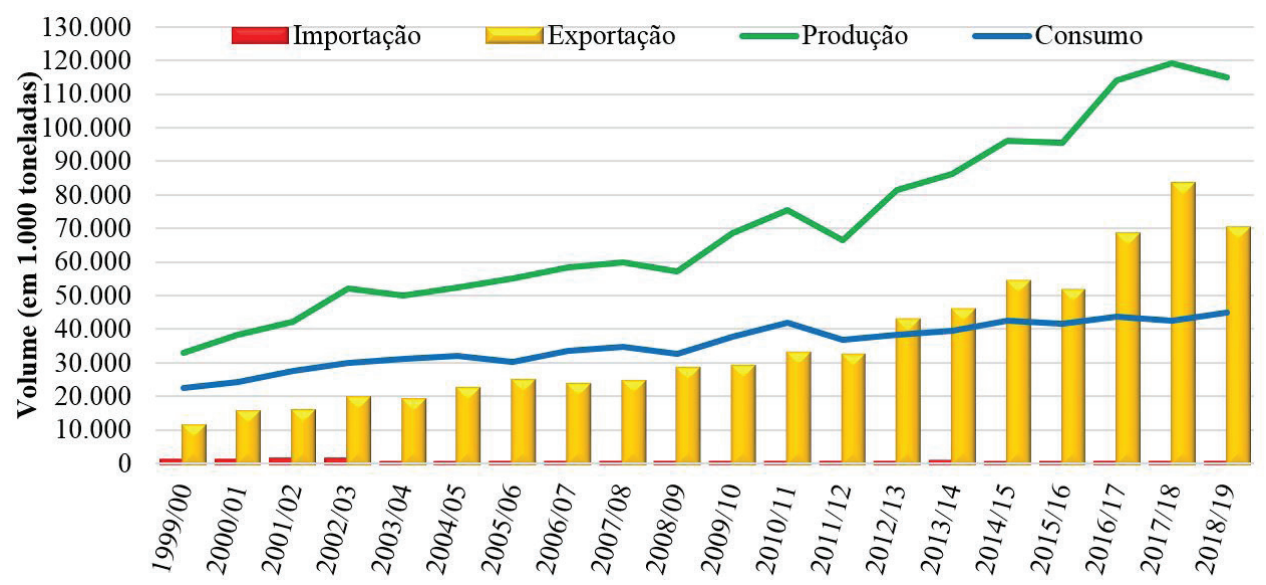

FIGURA 1 - Balanço nacional de oferta e demanda de soja em grãos no Brasil, em 1.000 toneladas, entre as safras 1999/2000 e 2018/19

Fonte: Conab (2021a)

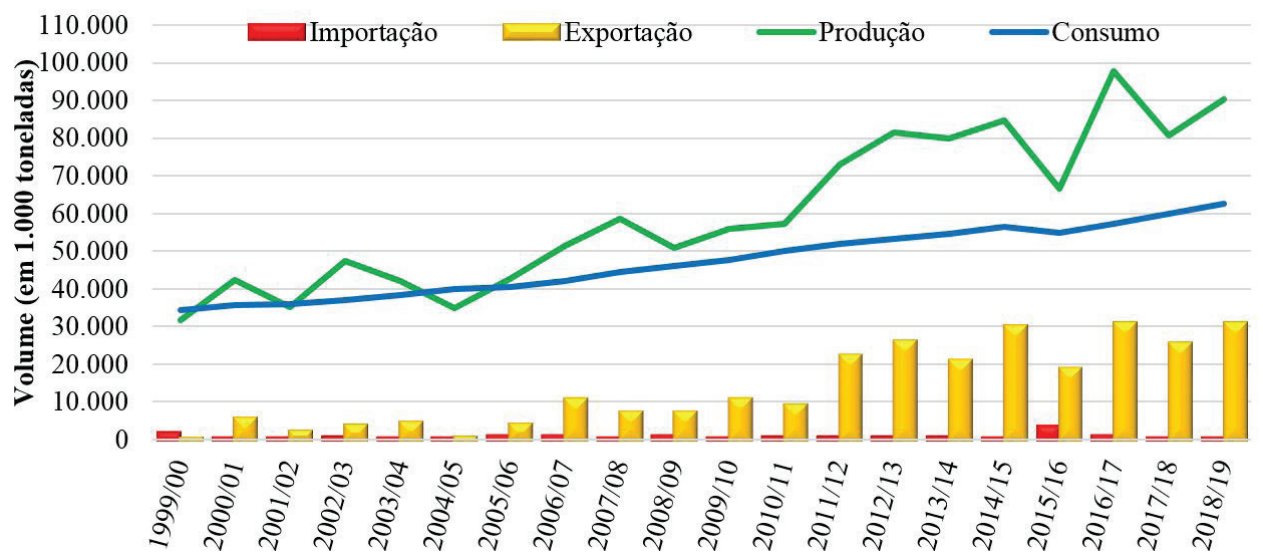

FIGURA 2 - Balanço nacional de oferta e demanda de milho em grãos no Brasil, em 1.000 toneladas, entre as safras $1999 / 2000$ e $2018 / 19$

Fonte: Conab (2021a)

O consumo doméstico detém um maior peso sobre a produção, representando média de $69,2 \%$ do total produzido entre as safras 2011/12 e 2018/19 (CONAB, 2021a). As importações não são expressivas, com exceção da safra 2015/16, em que fatores climáticos reduziram a produção interna e houve necessidade de se recorrer ao mercado externo para suprir a demanda nacional.

Em contraste com a soja e o milho, para a cultura do trigo o país se apresenta como importador líquido (Figura 3). Para os anos analisados, a produção de trigo atingiu seu maior volume na safra 2016/17, representando 58,4\% do consumo doméstico (CONAB, 2021a). De modo geral, o Brasil necessita importar mais de 50\% do total consumido. A produção oscila a cada ano, a depender especialmente das condições climáticas e, em menor intensidade, da atratividade dos preços no período que antecede o cultivo. Já o consumo apresenta tendência ligeiramente crescente ao longo dos últimos oito anos.

As exportações do trigo foram mais expressivas nas safras de 2009/10 a 2010/11, e de 2014/15 a 2015/16, chegando a 2,5 milhões de toneladas na safra 2010/11 (CONAB, 2021a). Este fato é explicado pelas diferenças de qualidade e aptidão para usos alimentícios humanos e animais diversos, assim como por incentivos governamentais para a comercialização, em que agentes vendedores aproveitaram a oportunidade para escoamento ao mercado externo. 
3.2 Evolução da área semeada das culturas da soja, milho e trigo no Sul do Brasil

Os estados do Sul do Brasil detinham a maior área semeada com soja do país durante a década de 1990 (Tabela 1). Entre os anos de 2000 e 2005, o estado de Mato Grosso duplicou a área com a cultura e passou a ser o maior estado em área semeada com soja, atingindo 9,7 milhões de hectares (ha) em 2018/19 (CONAB, 2021b). Ainda na safra 2018/19, a área semeada com soja no Rio Grande do Sul foi de 5,8 milhões de ha, segundo estado em termos de área semeada, seguido pelo Paraná com 5,4 milhões de ha.

Apesar de porcentagens representativas no Sul do país, a mesorregião do Centro-Oeste representou $44,9 \%$ da área total soja na safra 2018/19, ocupando a primeira posição em nível nacional (CONAB, 2021b). Não obstante, apesar da oferta crescente, a porcentagem da produção de soja no Sul do país vem sendo reduzida desde 1990/91, devido ao cultivo em novas fronteiras agrícolas, mostrando-se 26,2\% inferior ao Centro-Oeste na safra 2018/19 (CONAB, 2021b).

Em relação ao milho primeira safra, os estados do Paraná e do Rio Grande do Sul apresentaram as maiores porcentagens da década de 1990 até a safra 2008/09. Contudo, na safra 2009/10 Minas Gerais ultrapassou a ambos, detendo $15,1 \%$ da área semeada do país - o maior dentre os estados, enquanto o Rio Grande do Sul deteve 14,9\%, e o Paraná 11,6\% (CONAB, 20121b). Este fato se deve à redução nas áreas destinadas ao cereal nos estados do Sul, e não de um aumento em Minas Gerais. De modo geral, a área do milho primeira safra tem sido reduzida desde 2005/06 nos três estados do Sul, com reversão da tendência apenas em 2017/18. Em 2018/19, o Paraná representou $7,8 \%$ da área nacional de milho primeira safra, Santa Catarina, 7,3\%, e Rio Grande do Sul, 16,3\%.

Apesar da alta representatividade do milho primeira safra na região Sul, o Nordeste ocupou a primeira posição em relação à área total do país nos últimos anos-safras, alavancado pelo cultivo nos estados do Piauí e Bahia (CONAB, 2021b), ambos considerados de fronteira agrícola. Entretanto, quando se observam os dados de produção, o Sul do país representou 43,9\% do total produzido no Brasil na safra 2018/19, representando mais do dobro em relação ao Nordeste $(18,7 \%)$, sustentado pelas maiores produtividades agrícolas (CONAB, 2021b).

Já para o milho segunda safra, apesar de ter havido um crescimento de $864,8 \%$ na área da cultura no Sul do país entre 1990/91 e 2018/19, atingindo 2,2 milhões de ha na safra 2018/19, a região teve redução da participação sobre a área da cultura em nível nacional, sendo responsável por $17,5 \%$ do total semeado do Brasil. A região Centro-Oeste, com destaque para Mato Grosso $(37,8 \%)$, é a principal região produtora em nível nacional (CONAB, 2021b). Apenas o Paraná cultiva milho segunda safra no Sul, segundo a Conab (2021b), ocupando a segunda posição em termos de área semeada, perdendo para o Mato Grosso. Quando se observam os dados de produção, o Sul do país manteve a primeira posição até a safra 2000/2001, sendo superado pelo Centro-Oeste no ano-safra 2001/02, de forma que na safra 2018/19, a diferença de produção entre ambos chegou à 36,7 milhões de toneladas, equivalente a $271,8 \%$.

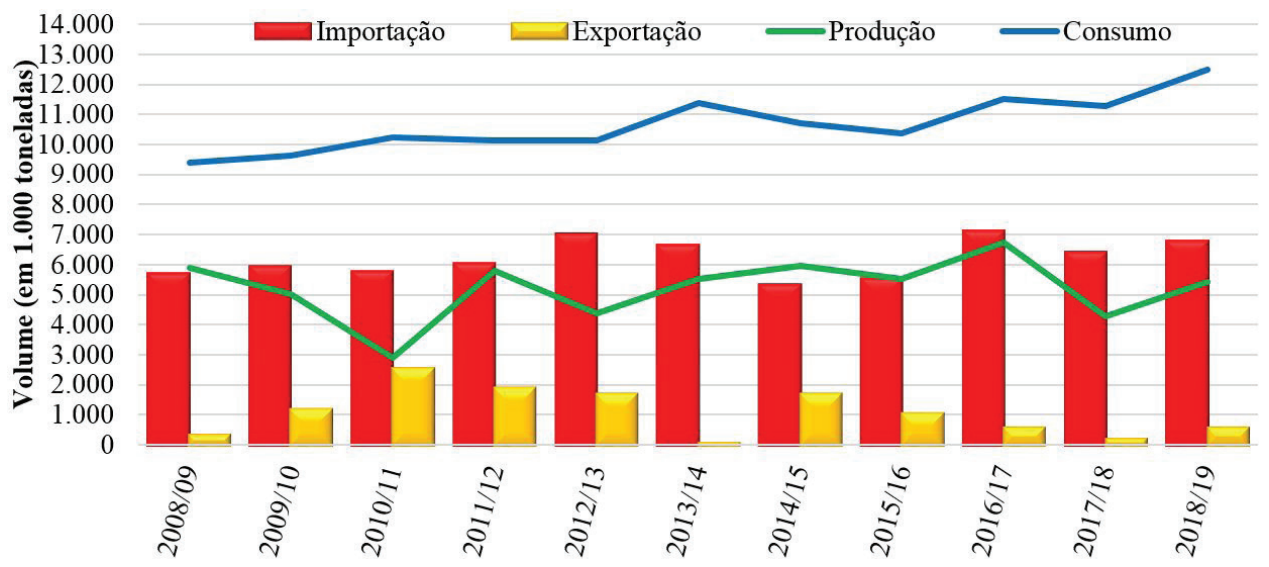

FIGURA 3 - Balanço nacional de oferta e demanda de trigo em grãos no Brasil, em 1.000 toneladas, entre as safras $1999 / 2000$ e $2018 / 19$

Fonte: Conab (2021a)

Organizações Rurais \& Agroindustriais, Lavras, v. 22, e1554, 2020 
TABELA 1 - Área semeada e produção total por mesorregião brasileira, em termos percentuais, para as culturas da soja, milho primeira e segunda safras, e trigo, para os anos agrícolas de 1990/91, 2000/01, 2010/11 e 2018/19

\begin{tabular}{|c|c|c|c|c|c|c|c|c|c|}
\hline \multirow{2}{*}{ Cultura } & \multirow{2}{*}{ Grande região } & 1990/91 & $2000 / 01$ & $2010 / 11$ & $2018 / 19$ & 1990/91 & $2000 / 01$ & $2010 / 11$ & $2018 / 19$ \\
\hline & & \multicolumn{4}{|c|}{ Área (ha) } & \multicolumn{4}{|c|}{ Produção (mil t) } \\
\hline \multirow{5}{*}{ Soja } & Norte & $0,1 \%$ & $0,7 \%$ & $2,7 \%$ & $5,5 \%$ & $0,1 \%$ & $0,6 \%$ & $2,6 \%$ & $5,2 \%$ \\
\hline & Nordeste & $2,9 \%$ & $6,9 \%$ & $8,0 \%$ & $9,3 \%$ & $3,7 \%$ & $5,4 \%$ & $8,3 \%$ & $9,2 \%$ \\
\hline & Centro-Oeste & $30,2 \%$ & $41,2 \%$ & $44,7 \%$ & $44,9 \%$ & $43,3 \%$ & $44,2 \%$ & $45,1 \%$ & $45,8 \%$ \\
\hline & Sudeste & $10,0 \%$ & $8,4 \%$ & $6,8 \%$ & $7,2 \%$ & $12,5 \%$ & $7,5 \%$ & $6,1 \%$ & $7,0 \%$ \\
\hline & Sul & $56,8 \%$ & $42,8 \%$ & $37,8 \%$ & $33,1 \%$ & $40,4 \%$ & $42,3 \%$ & $37,9 \%$ & $32,9 \%$ \\
\hline \multirow{5}{*}{$\begin{array}{l}\text { Milho primeira } \\
\text { safra }\end{array}$} & Norte & $3,4 \%$ & $5,3 \%$ & $5,7 \%$ & $5,6 \%$ & $2,7 \%$ & $2,6 \%$ & $3,2 \%$ & $3,2 \%$ \\
\hline & Nordeste & $21,4 \%$ & $21,8 \%$ & $32,8 \%$ & $31,5 \%$ & $8,2 \%$ & $5,2 \%$ & $13,7 \%$ & $18,7 \%$ \\
\hline & Centro-Oeste & $12,0 \%$ & $11,4 \%$ & $6,9 \%$ & $7,5 \%$ & $19,2 \%$ & $16,0 \%$ & $11,4 \%$ & $9,8 \%$ \\
\hline & Sudeste & $23,3 \%$ & $19,7 \%$ & $22,9 \%$ & $24,1 \%$ & $33,5 \%$ & $21,5 \%$ & $27,6 \%$ & $24,5 \%$ \\
\hline & Sul & $40,0 \%$ & $41,8 \%$ & $31,6 \%$ & $31,3 \%$ & $36,3 \%$ & $54,8 \%$ & $44,1 \%$ & $43,9 \%$ \\
\hline \multirow{5}{*}{$\begin{array}{l}\text { Milho segunda } \\
\text { safra }\end{array}$} & Norte & $0,0 \%$ & $0,0 \%$ & $1,4 \%$ & $3,7 \%$ & $0,0 \%$ & $0,0 \%$ & $1,3 \%$ & $3,0 \%$ \\
\hline & Nordeste & $36,9 \%$ & $11,6 \%$ & $10,4 \%$ & $8,2 \%$ & $12,6 \%$ & $1,9 \%$ & $6,0 \%$ & $2,3 \%$ \\
\hline & Centro-Oeste & $5,6 \%$ & $33,9 \%$ & $53,9 \%$ & $63,5 \%$ & $7,2 \%$ & $38,7 \%$ & $59,3 \%$ & $68,6 \%$ \\
\hline & Sudeste & $28,3 \%$ & $15,6 \%$ & $6,4 \%$ & $7,1 \%$ & $45,3 \%$ & $14,0 \%$ & $5,8 \%$ & $7,6 \%$ \\
\hline & Sul & $29,1 \%$ & $38,9 \%$ & $27,8 \%$ & $17,5 \%$ & $34,9 \%$ & $45,4 \%$ & $27,6 \%$ & $18,4 \%$ \\
\hline \multirow{5}{*}{ Trigo } & Norte & $0,0 \%$ & $0,0 \%$ & $0,0 \%$ & $0,0 \%$ & $0,0 \%$ & $0,0 \%$ & $0,0 \%$ & $0,0 \%$ \\
\hline & Nordeste & $0,0 \%$ & $0,0 \%$ & $0,0 \%$ & $0,2 \%$ & $0,0 \%$ & $0,0 \%$ & $0,0 \%$ & $0,6 \%$ \\
\hline & Centro-Oeste & $6,4 \%$ & $4,9 \%$ & $2,6 \%$ & $2,1 \%$ & $5,8 \%$ & $5,1 \%$ & $2,6 \%$ & $2,6 \%$ \\
\hline & Sudeste & $6,3 \%$ & $1,6 \%$ & $3,1 \%$ & $7,7 \%$ & $6,7 \%$ & $3,0 \%$ & $3,3 \%$ & $7,4 \%$ \\
\hline & Sul & $87,4 \%$ & $93,4 \%$ & $94,3 \%$ & $90,0 \%$ & $87,6 \%$ & $91,9 \%$ & $94,1 \%$ & $89,4 \%$ \\
\hline
\end{tabular}

Fonte: Conab (2021b)

Em relação ao trigo, o estado do Paraná representou, na safra $2018 / 19,53,8 \%$ da área total semeada no Brasil, Santa Catarina, 2,8\%, e Rio Grande do Sul, 33,4\%, compondo a grande região com a maior área no país, seguido com grande folga pelo Sudeste (CONAB, 2021b). Este fato se origina das condições climáticas do Sul do país, que favorecem o cultivo de trigo em detrimento de culturas concorrentes em área, como o milho, a partir da porção Sul do Paraná. A área destinada ao trigo tem aumentado no Sudeste, atingindo $7,7 \%$ na safra $2018 / 19$, contrariamente ao observado no Centro-Oeste, cuja área em 2018/19 representou 2,1\% em relação ao total. Em relação à produção, o Sul detém por volta de $90 \%$ do total nacional desde a década de 1990. A participação do Sudeste na produção total vem aumentando ao longo da década de 2010 , atingindo $7,4 \%$ na safra 2018/19.

\subsection{Evolução histórica da área semeada com soja, milho e trigo no Sul do Brasil}

Para apresentar a evolução histórica de cada cultura temporária de interesse, cada estado do Sul foi subdividido em duas regiões principais, conforme Quadro 1 e Figura 4. A subdivisão definida foi realizada pelos próprios autores, buscando agrupar regiões que apresentam condições de cultivo e sistemas produtivos similares entre si, com base principalmente nos dados de área cultivada do IBGE (2018), e nos dados coletados em painel pelo CEPEA/CNA(2019). Como se verá adiante, o agrupamento proposto é embasado nos dados apresentados nos resultados.

$\mathrm{Na}$ Figura 5 é representada a evolução histórica da área semeada com soja, segundo dados da Produção Agrícola Municipal disponibilizados pelo IBGE (2018). Verifica-se um aumento da área com soja no Sul do Brasil 
como um todo, com maior expressão entre os anos 2000 e 2005, e entre os anos 2010 e 2015. De modo geral, houve um acréscimo de área de 136,7\% no Paraná entre 1990 e 2018,
$82,5 \%$ em Santa Catarina, e $62,2 \%$ no Rio Grande do Sul. O cultivo saltou de um total de 6,2 milhões de hectares (ha) em 1990 no Sul do Brasil, para 11,8 milhões de ha em 2018.

Quadro 1 - Subdivisão dos estados do Sul do Brasil e respectivas mesorregiões pertencentes

\begin{tabular}{|ccc|}
\hline Centro-Norte Ocidental do Paraná & Centro-Oeste de Santa Catarina & Centro-Norte do Rio Grande do Sul \\
Noroeste Paranaense & Oeste Catarinense & Noroeste Rio-grandense \\
Centro Ocidental Paranaense & Norte Catarinense & Nordeste Rio-grandense \\
Norte Central Paranaense & Serrana & Centro Ocidental Rio-grandense \\
Norte Pioneiro Paranaense & & Centro Oriental Rio-grandense \\
Oeste Paranaense & & \\
Centro-Sul Oriental do Paraná & Costa-Leste de Santa Catarina & Sul do Rio Grande do Sul \\
Centro Oriental Paranaense & Vale do Itajaí & Metropolitana de Porto Alegre \\
Sudoeste Paranaense & Grande Florianópolis & Sudoeste Rio-grandense \\
Centro-Sul Paranaense & Sul Catarinense & Sudeste Rio-grandense \\
Sudeste Paranaense & & \\
Metropolitana de Curitiba & & \\
\hline
\end{tabular}

Fonte: elaborado pelos autores

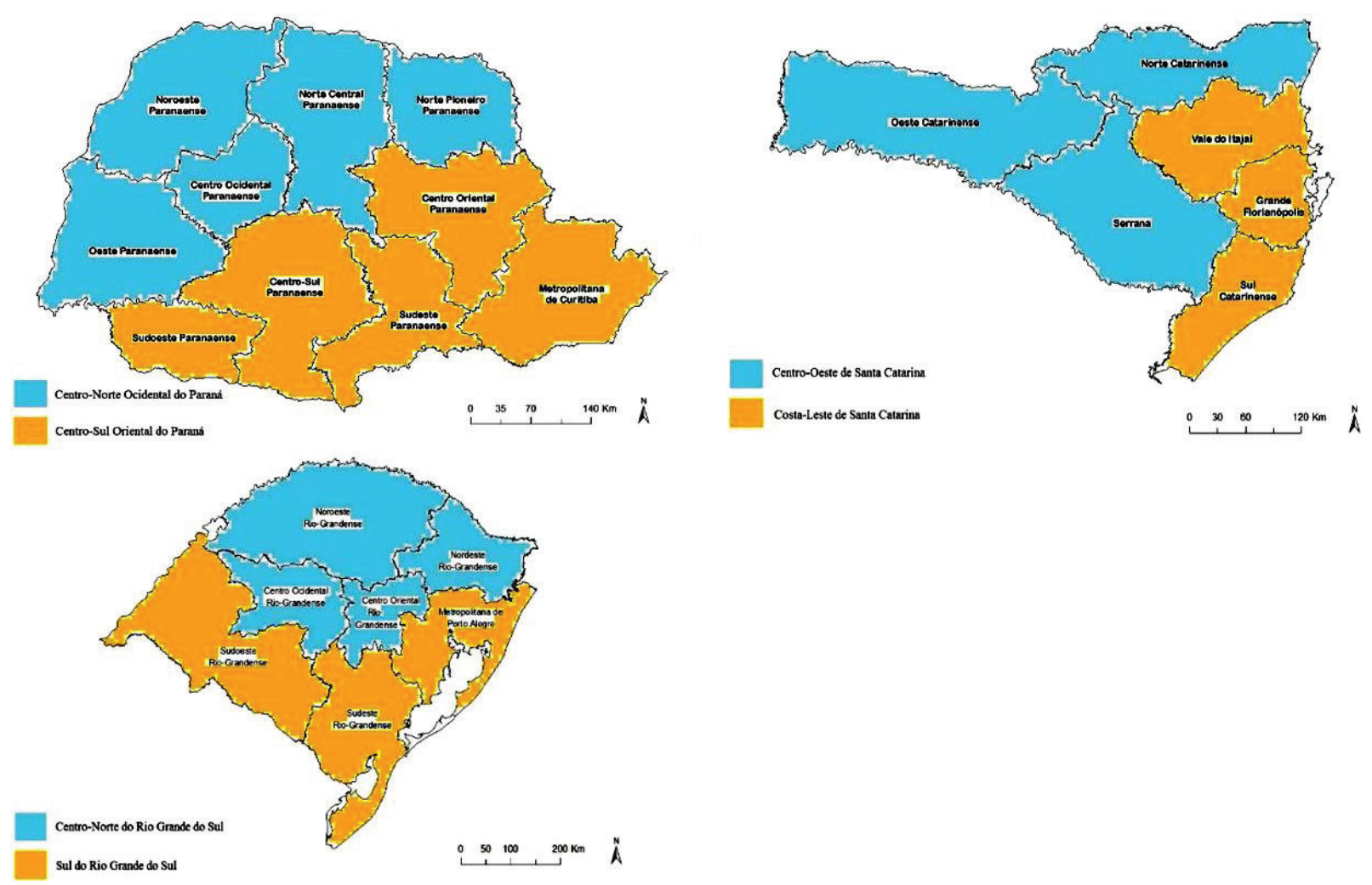

FIGURA 4 - Subdivisão dos estados do Sul do Brasil e respectivas mesorregiões Fonte: elaborado pelos autores (2020) 


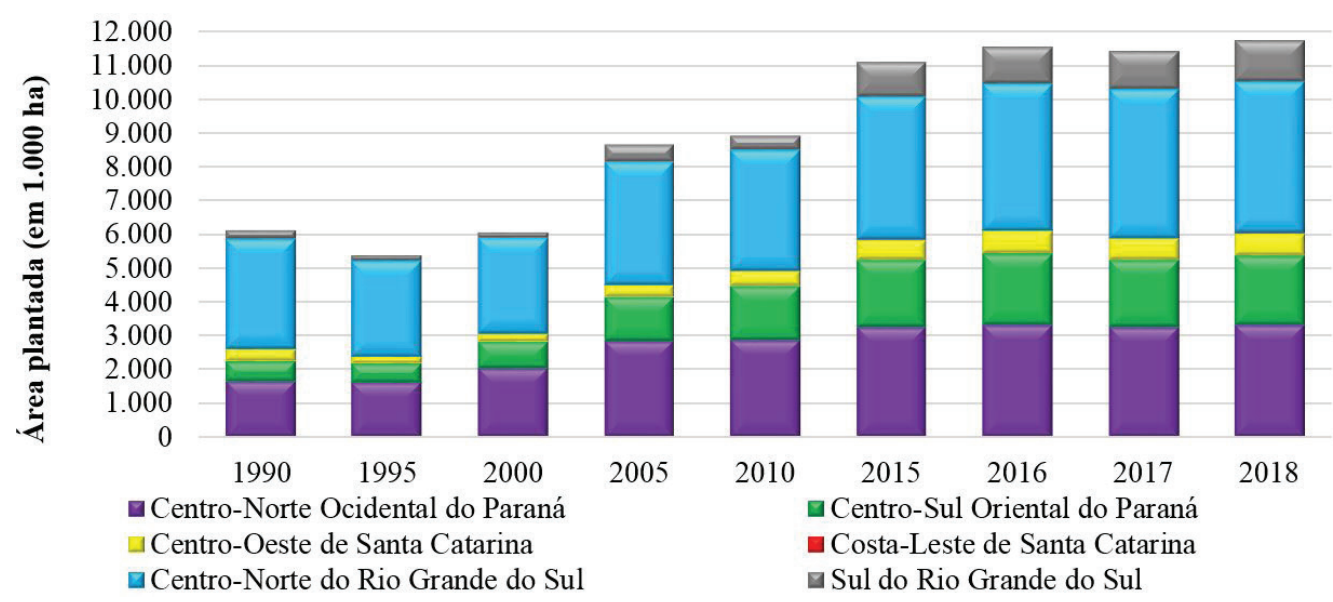

FIGURA 5 - Evolução histórica da área semeada com soja, nas seis subdivisões delimitadas, nos estados do Paraná, Santa Catarina e Rio Grande do Sul, em anos selecionados Fonte: IBGE (2018)

Ao comparar estes números com dados estruturais do IBGE (2017) sobre o uso da terra, verifica-se que nos estados do Paraná e do Rio Grande do Sul a área destinada a lavouras temporárias vem aumentando desde 1995, enquanto que a área em Santa Catarina reduziu entre 2006 e 2017, ou seja, há concorrência por área com culturas não temporárias e atividades em Santa Catarina. Segundo Emygdio, Rosa e Oliveira (2017), o cultivo de soja no Rio Grande do Sul vem tomando o espaço do arroz, principalmente em sistema de rotação de culturas, com o intuito de controlar infestação do arroz vermelho - a principal planta daninha responsável pela queda de produtividade. Outro dado interessante sobre a soja se refere à expressividade de seu semeio no Rio Grande do Sul, representando quase $50 \%$ da área total de soja do Sul do país, seguido de perto pelo Paraná, com $46 \%$, sendo apenas 4\% cultivados em Santa Catarina (IBGE, 2018).

Os dados relacionados ao milho cultivado na primeira e na segunda safras são dispostos na Figura 6 e na Figura 7. $\mathrm{Na}$ área semeada com milho primeira safra, verifica-se uma tendência de queda entre 2003 e 2018 em todos os estados da região Sul (IBGE, 2018). De 3,7 milhões de ha cultivados em 2003, no Sul do Brasil como um todo, restou 1,4 milhão de ha em 2018, ou seja, menos da metade. No período, houve redução de área com a cultura em todos os estados, sendo no Paraná de 76,0\%, em Santa Catarina, de 61,4\%, e no Rio Grande do Sul, de $50,2 \%$. A área de milho primeira safra do Rio Grande do Sul representou quase metade da área total destinada à essa cultura no Sul do país em 2018, restando um quarto para o Paraná e outro quarto para Santa Catarina (IBGE, 2018).
O milho segunda safra é cultivado apenas no estado do Paraná, favorecido pela antecipação do cultivo de soja e pelas condições climáticas que viabilizam o cultivo em sucessão. Conforme demonstrado na Tabela 3, mais de três quartos do milho total cultivado nesse estado é referente à segunda safra. A despeito de uma redução de 13,7\% no cultivo de milho segunda safra no Centro-Sul Oriental do Paraná, tem-se um aumento de 56,4\% no Centro-Norte Ocidental, entre os anos de 2003 e 2018 (IBGE, 2018).

O ano de 1990 retratou o maior patamar do cultivo de trigo no Sul do Brasil, com destaque para a região CentroNorte Ocidental do Paraná (Figura 8). Em 1995, houve uma queda brusca de área semeada, com posterior tendência de recuperação até 2015. Entre 1990 e 2018, a área com trigo reduziu 40,4\% no Paraná, 49,3\% em Santa Catarina, e 28,2\% no Rio Grande do Sul. De quase três milhões de ha cultivados em 1990 no Sul do país, restou 1,8 milhão de ha em 2018.

Em seguida, apresenta-se a metodologia do estudo, visando caracterizar a dinâmica produtiva dos cultivos de grãos e da propriedade típica regional no Sul do Brasil

\section{METODOLOGIA}

Os dados utilizados neste estudo foram coletados e disponibilizados pelo Centro de Estudos Avançados em Economia Aplicada, sediado na Escola Superior de Agricultura "Luiz de Queiroz" da Universidade de São Paulo, em parceria com a Confederação da Agricultura e Pecuária do Brasil, no âmbito do Projeto Campo Futuro, refletindo a dinâmica real da produção de grãos nas regiões 
em estudo (CEPEA/CNA, 2019). As safras disponíveis para as análises englobam aquelas entre 2012/13 e 2018/19 para as regiões de Cascavel/PR, Londrina/PR, Castro/PR,
Guarapuava/PR, Carazinho/RS e Tupanciretã/RS, e entre 2013/14 e 2018/19 para as regiões de Campos Novos/SC e Xanxerê/SC (CEPEA/CNA, 2019).

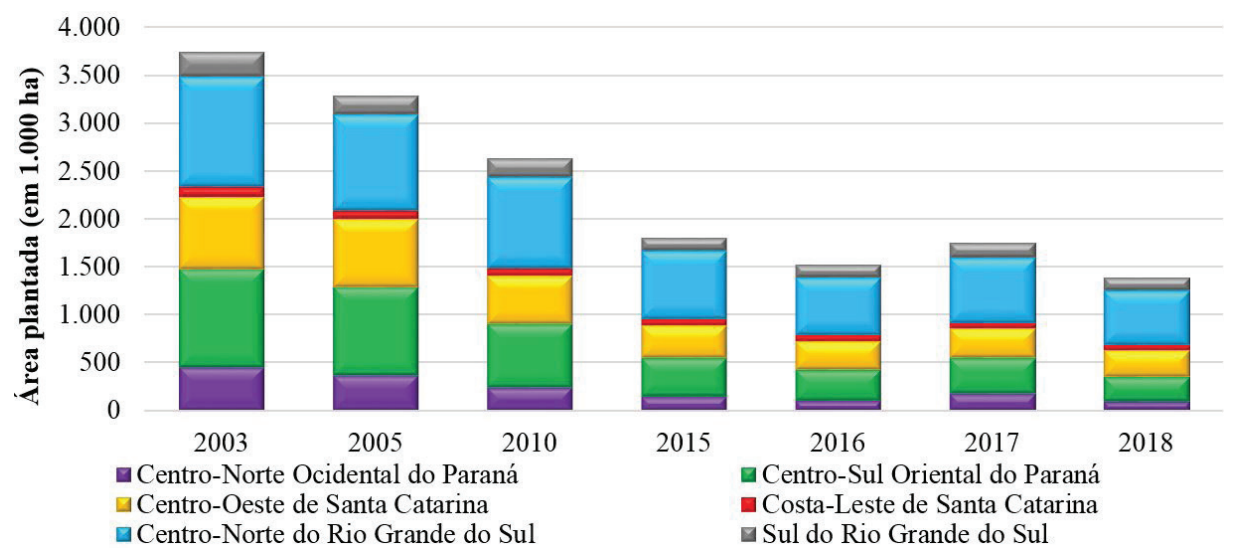

FIGURA 6 - Evolução histórica da área semeada com milho primeira safra, nas seis subdivisões delimitadas, nos estados do Paraná, Santa Catarina e Rio Grande do Sul, em anos selecionados Fonte: IBGE (2018)

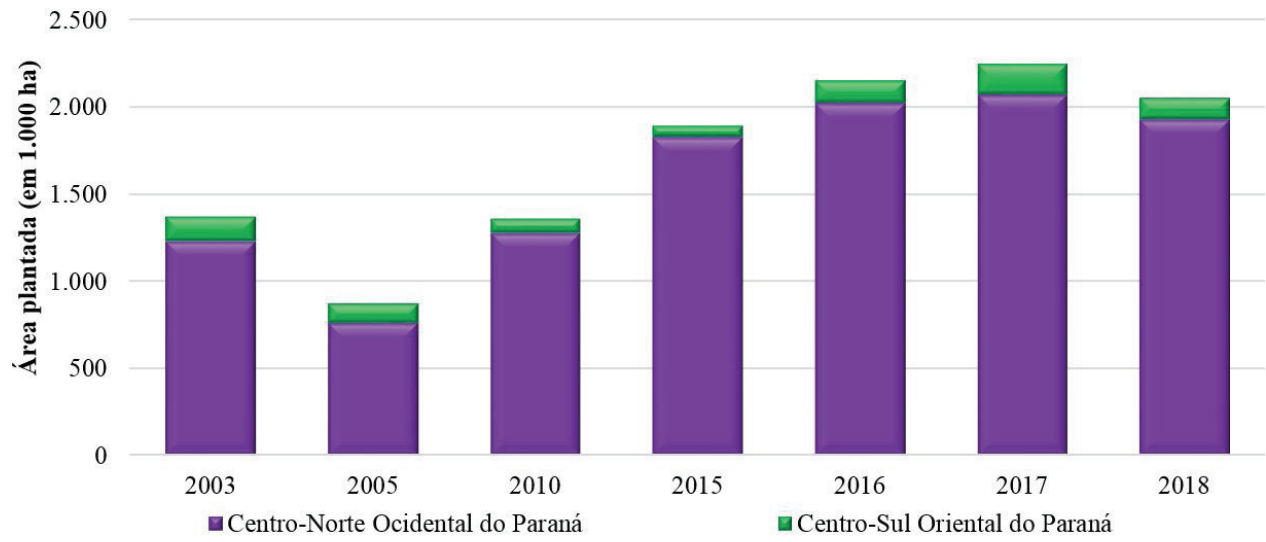

FIGURA 7 - Evolução histórica da área semeada com milho segunda safra, nas seis subdivisões delimitadas, nos estados do Paraná, Santa Catarina e Rio Grande do Sul, em anos selecionados

Fonte: IBGE (2018)

TABELA 3 - Área e representativa dos cultivos de milho de primeira e segunda safras no estado do Paraná, em anos selecionados.

\begin{tabular}{ccccccccc}
\hline Safra & Tipo de dados & 2003 & 2005 & 2010 & 2015 & 2016 & 2017 & 2018 \\
\hline Milho primeira & Valor absoluto (ha) & 1.471 .316 & 1.288 .373 & 897.280 & 548.097 & 422.686 & 550.113 & 353.666 \\
safra & $\%$ & $51,7 \%$ & $59,5 \%$ & $39,8 \%$ & $22,5 \%$ & $16,4 \%$ & $19,7 \%$ & $14,7 \%$ \\
Milho segunda & Valor absoluto (ha) & 1.374 .738 & 878.620 & 1.359 .751 & 1.891 .303 & 2.150 .567 & 2.249 .115 & 2.050 .631 \\
safra & $\%$ & $48,3 \%$ & $40,5 \%$ & $60,2 \%$ & $77,5 \%$ & $83,6 \%$ & $80,3 \%$ & $85,3 \%$ \\
\hline
\end{tabular}

Fonte: IBGE (2018)

Nota: * em relação ao milho total cultivado no Sul do Brasil 


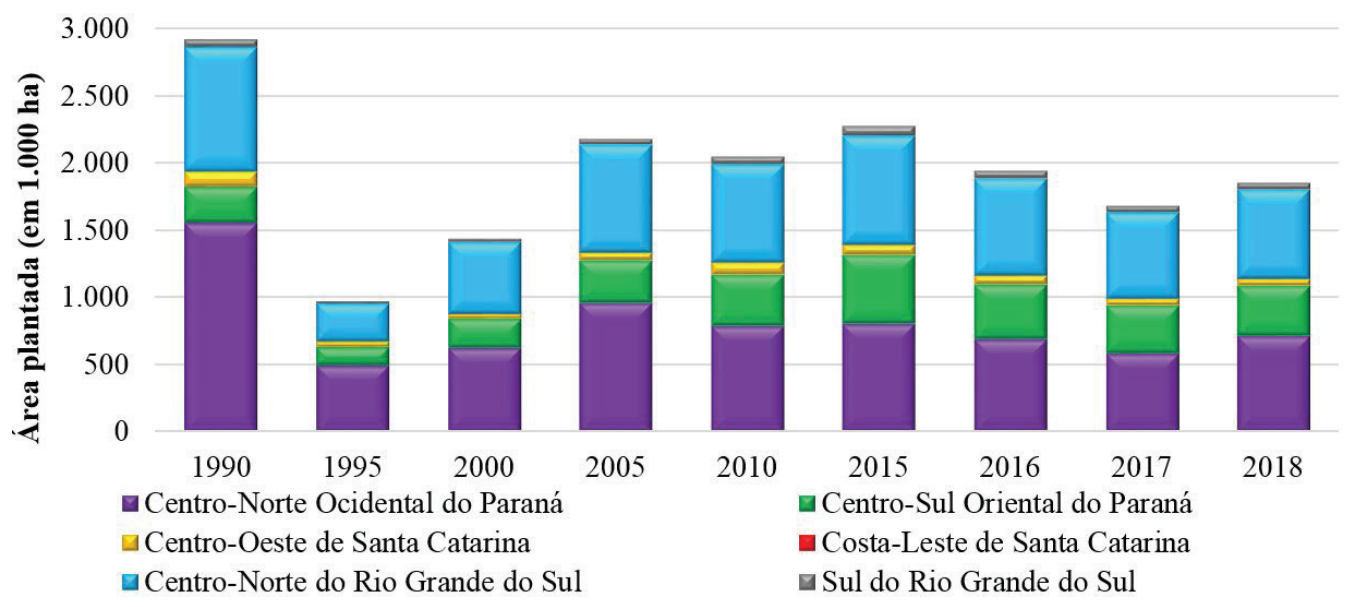

FIGURA 8 - Evolução histórica da área semeada com milho segunda safra, nas seis subdivisões delimitadas, nos estados do Paraná, Santa Catarina e Rio Grande do Sul, em anos selecionados Fonte: IBGE (2018)

A coleta se deu por meio de metodologia painel (DEBLITZ et al., 1998; CHIBANDA et al., 2020) com periodicidade anual, nas diversas regiões de estudo, buscando-se a definição de uma propriedade típica de cada região. Para isto, uma vez ao ano, desloca-se para as respectivas regiões e, juntamente com outros agentes do setor (produtores, revendas de insumos, cooperativas, consultores independentes, funcionários públicos, dentre outros), intermedia-se discussões para se atingir o consenso do grupo sobre os dados, extraindo o conhecimento e informações dos participantes (DEBLITZ et al., 1998).

Por propriedade típica entende-se a característica modal de produção em cada região (FEUZ; SKOLD, 1991; CHIBANDA et al., 2020), que neste estudo teve como foco as culturas temporárias. Desta forma, busca-se definir a propriedade modal com base no sistema produtivo regional, descrevendo todos os itens de ativos imobilizados e de atividades operacionais, de forma que represente as características produtivas em cada região (ELLIOTT, 1928; CHIBANDA et al., 2020).

Para o levantamento da propriedade modal, iniciase com a caracterização do tamanho, e da repartição entre área própria e arrendada. Parte-se para a composição de culturas e tecnologias, semeadas em primeira e segunda safra, assim como as produtividades e preços médios de venda. Para cada cultura e tecnologia, definem-se os tratos culturais realizados. Levanta-se também a composição de máquinas, equipamentos, benfeitorias e utilitários da propriedade, com base em seu tamanho. Outros componentes captados envolvem forma de financiamento da produção, seguro agrícola, forma de comercialização, dentre outros custos diversos. Procedimento similar pode ser encontrado em Osaki et al. (2019).

As culturas temporárias consideradas no estudo envolvem aquelas comumente cultivadas nas respectivas regiões, nos anos selecionados, conforme CEPEA/CNA (2019), constituídas basicamente por soja, milho, trigo. Outras culturas menos representativas, mas que foram captadas em painel, isto é, semeadas por produtores de determinada região em determinado ano safra, também foram incluídas: feijão, cevada, aveia branca e canola. As composições dos sistemas produtivos de cada propriedade típica regional serão discutidas nos resultados, elencando possibilidades de semeio tanto na primeira quanto segunda safra. Um aspecto importante se refere à distinção entre tecnologias dos cultivares para realização das análises, de forma que em uma mesma safra as culturas da soja e do milho podem apresentar mais de uma tecnologia, como de sementes convencionais e geneticamente modificadas.

\section{RESULTADOS E DISCUSSÃO}

Conforme informações obtidas em CEPEA/ CNA (2019), os dados envolvem os cultivos para um ano agrícola em cada propriedade modal, englobando a primeira safra e a segunda safra, quando presente. $O$ tratamento da propriedade como um todo incorpora, por um lado, as sinergias e vantagens complementares, de maneira a obter resultados superiores à simples soma de resultados individuais por cultura. 
Na Tabela 4 são apresentados os usos das áreas nas propriedades típicas de quatro regiões do Paraná, em anos selecionados. A soja cultivada com semente geneticamente modificada (OGM) inclui as tecnologias com tolerância ao herbicida glifosato e a tolerante ao herbicida glifosato mais resistência a insetos (Bacillus thuringiensis - $\mathrm{Bt}$ ), especialmente lagartas. Para o milho OGM, inclui-se sementes que irão germinar plantas com a tolerância ao herbicida glifosato, adotado majoritariamente nas áreas de refúgio na safra 2018/19 em detrimento do convencional, e o milho Bt (ordem Lepidoptera), usualmente contendo de forma agregada a tolerância a herbicidas. Para as demais culturas, a tecnologia adotada se refere a sementes convencionais, isto é, não geneticamente modificada (NOGM). A seguir são feitas considerações sobre algumas alterações significativas que influenciaram na composição da propriedade ao longo do tempo.

As informações obtidas, com foco em culturas temporárias, apontam que no estado do Paraná a primeira safra é composta predominantemente por soja e milho para as quatro regiões delimitadas (Londrina/PR, Cascavel/ PR, Castro/PR e Guarapuava/PR). Ao se considerar o cultivo para fins comerciais, a segunda safra do Paraná é composta principalmente por milho e trigo, com menor representatividade para a cevada e o feijão.

As regiões de Londrina/PR e Cascavel/PR, ambas situadas no Centro-Norte Ocidental do Paraná, apresentam tendência de aumento do milho segunda safraprincipalmente geneticamente modificado - em detrimento do trigo. Em contraste, no Centro-Sul Oriental do Paraná, as regiões de Castro/PR e Guarapuava/PR não semeiam o milho segunda safra, apresentando predominância do trigo, com inclusão pouco representativa de feijão e cevada. Este fato é comprovado por Franchini et al. (2012), explicado pelo zoneamento climático das culturas, considerando temperatura, disponibilidade hídrica, dentre outros fatores edafoclimáticos, em que nas regiões oeste e norte o cultivo de soja ocorre logo após o término do vazio sanitário (em geral, 15 de setembro), enquanto na metade sul do estado o cultivo ocorre posteriormente. Além disso, mais ao sul do estado o clima é mais ameno, com maiores possibilidades de geadas, aumentando o risco de cultivo de milho segunda safra.

Em se tratando da região de Londrina/PR, nota-se ausência do cultivo de milho na primeira safra, sendo destinada integralmente para o cultivo de soja. Para a segunda safra, há cultivo de milho em $80 \%$ da área, sendo o restante destinado ao pousio ou cobertura verde. $\mathrm{O}$ mesmo é verificado para Cascavel/PR, mas o trigo tem sido cultivado nos $20 \%$ restantes da área de segunda safra desde 2016/17.

Quando se considera o cultivo da segunda safra objetivando a melhoria agronômica do sistema como um todo, verifica-se porcentagem expressiva do cultivo de aveia preta, resultando em ausência de áreas de pousio exceto em Londrina/PR, cuja proporção foi inferior a 20\% da área de segunda safra. Segundo Debiasi et al. (2010), há correlação positiva com a produtividade das culturas subsequentes ao cultivo da aveia preta, como soja e milho, devido ao aumento da matéria-orgânica presente no solo e da menor compactação nas camadas superficiais do solo.

Para a região de Castro/PR, há duas particularidades não presentes nas outras três regiões. A primeira delas é concernente ao semeio de feijão primeira safra, que representou, nos últimos anos, cerca de $20 \%$ da área total da propriedade típica - exceto na safra 2018/19, cuja redução da área de feijão levou ao consequente aumento da área de soja, cultivada em expressivos $85 \%$ da área de primeira safra. A segunda se refere à expressividade de cultivares de soja e milho não geneticamente modificadas, isto é, convencionais, e que garante um adicional de prêmio sobre o valor de comercialização, contribuindo para maiores rentabilidades - especialmente sobre a soja. $\mathrm{O}$ milho de primeira safra tem sido cultivado em apenas $10 \%$ da área nas safras analisadas, sendo que apenas $1 \%$ ou $2 \%$ é referente ao NOGM.

$\mathrm{Na}$ região de Guarapuava/PR, a propriedade típica cultivou 330 hectares em todos os anos analisados. Na primeira safra, entre $70 \%$ e $90 \%$ da área foi cultivada com soja, sendo o restante dedicado praticamente ao milho de primeira safra - somente na temporada 2016/17 houve uma pequena parcela de área dedicada ao feijão. Na segunda safra, ao redor de dois terços da área disponível foi utilizada com cobertura verde, ou seja, apenas uma parcela da área foi cultivada com culturas comerciais, especialmente trigo. Esta área de trigo foi sendo reduzida ao longo dos anos-safras, sendo que em anos recentes o cultivo de feijão ganhou um pouco mais de espaço, devido à sua atratividade em termos de rentabilidade.

Observando o tamanho das propriedades típicas do Paraná, nota-se uma tendência de aumento para a região de Londrina/PR nos últimos três anos em relação aos anteriores, refletindo o início da prática de arrendamento, de forma que houve uma adição de 48 ha de área arrendada, aos 97 ha de área própria. As regiões de Cascavel/PR, Castro/PR e Guarapuava/PR tem mantido a área total cultivável. 
TABELA 4 - Sistemas produtivos das propriedades típicas do estado do Paraná, entre os anos agrícolas de 2012/13 e $2018 / 19$

\begin{tabular}{|c|c|c|c|c|c|c|c|c|c|c|c|c|c|c|}
\hline \multirow[t]{2}{*}{ Ano-safra } & \multirow{2}{*}{$\begin{array}{c}\text { Área de } \\
1^{\text {a Safra }} \\
\text { (ha) }{ }^{1}\end{array}$} & \multirow{2}{*}{$\begin{array}{c}\text { Área de } \\
2^{2 \mathrm{a}} \mathrm{Safra} \\
\text { (ha) }\end{array}$} & \multicolumn{5}{|c|}{ Primeira Safra $^{2}$} & \multicolumn{5}{|c|}{ Segunda Safra Comercial ${ }^{2}$} & \multicolumn{2}{|c|}{$\begin{array}{l}\text { Segunda Safra } \\
\text { Cobert. Verde } \\
\text { ou Pousio }\end{array}$} \\
\hline & & & $\begin{array}{c}\text { Soja } \\
\text { NOGM }\end{array}$ & $\begin{array}{c}\text { Soja } \\
\text { OGM } \\
\end{array}$ & $\begin{array}{c}\text { Milho } \\
\text { NOGM }\end{array}$ & $\begin{array}{l}\text { Milho } \\
\text { OGM }\end{array}$ & Feijão ${ }^{3}$ & $\begin{array}{c}\text { Milho } \\
\text { NOGM }\end{array}$ & $\begin{array}{l}\text { Milho } \\
\text { OGM }\end{array}$ & Feijão $^{3}$ & Trigo & Cevada & $\begin{array}{l}\text { Aveia } \\
\text { Preta }\end{array}$ & Pousio \\
\hline \multicolumn{15}{|c|}{ Região: Londrina/PR } \\
\hline $2012 / 13$ & 97 & 97 & - & $100 \%$ & - & - & - & $4 \%$ & $72 \%$ & - & $24 \%$ & - & - & - \\
\hline 2013/14 & 97 & 87 & - & $100 \%$ & - & - & - & $6 \%$ & $54 \%$ & - & $30 \%$ & - & - & $10 \%$ \\
\hline 2014/15 & 97 & 82 & - & $100 \%$ & - & - & - & - & $70 \%$ & - & $15 \%$ & - & - & $15 \%$ \\
\hline $2015 / 16$ & 97 & 97 & - & $100 \%$ & - & - & - & $20 \%$ & $80 \%$ & - & - & - & - & - \\
\hline 2016/17 & 145 & 145 & - & $100 \%$ & - & - & - & - & $100 \%$ & - & - & - & - & - \\
\hline $2017 / 18$ & 145 & 116 & - & $100 \%$ & - & - & - & $8 \%$ & $72 \%$ & - & - & - & $20 \%$ & - \\
\hline 2018/19 & 145 & 116 & - & $100 \%$ & - & - & - & - & $80 \%$ & - & - & - & - & $20 \%$ \\
\hline \multicolumn{15}{|c|}{ Região: Cascavel/PR } \\
\hline $2012 / 13$ & 65 & 51 & - & $85 \%$ & - & $15 \%$ & - & - & $68 \%$ & - & $10 \%$ & - & $22 \%$ & - \\
\hline $2013 / 14$ & 65 & 64 & - & $95 \%$ & - & $5 \%$ & - & $8 \%$ & $80 \%$ & - & $10 \%$ & - & $2 \%$ & - \\
\hline 2014/15 & 65 & 59 & - & $100 \%$ & - & - & - & - & $70 \%$ & - & $20 \%$ & - & $10 \%$ & - \\
\hline $2015 / 16$ & 65 & 52 & - & $100 \%$ & - & - & - & - & $72 \%$ & - & $8 \%$ & - & $20 \%$ & - \\
\hline 2016/17 & 65 & 65 & - & $100 \%$ & - & - & - & - & $60 \%$ & - & $40 \%$ & - & - & - \\
\hline $2017 / 18$ & 65 & 65 & - & $100 \%$ & - & - & - & - & $80 \%$ & - & $20 \%$ & - & - & - \\
\hline 2018/19 & 65 & 65 & - & $100 \%$ & - & - & - & $4 \%$ & $81 \%$ & - & $15 \%$ & - & - & - \\
\hline \multicolumn{15}{|c|}{ Região: Guarapuava/PR } \\
\hline $2012 / 13$ & 330 & 116 & - & $75 \%$ & - & $25 \%$ & - & - & - & - & $25 \%$ & $10 \%$ & $65 \%$ & - \\
\hline $2013 / 14$ & 330 & 116 & - & $75 \%$ & $3 \%$ & $23 \%$ & - & - & - & - & $25 \%$ & $10 \%$ & $65 \%$ & - \\
\hline $2014 / 15$ & 330 & 116 & - & $75 \%$ & $1 \%$ & $24 \%$ & - & - & - & - & $25 \%$ & $10 \%$ & $65 \%$ & - \\
\hline $2015 / 16$ & 330 & 99 & - & $90 \%$ & $1 \%$ & $9 \%$ & - & - & - & - & $25 \%$ & $5 \%$ & $70 \%$ & - \\
\hline $2016 / 17$ & 330 & 102 & - & $65 \%$ & $3 \%$ & $27 \%$ & $5 \%$ & - & - & $6 \%$ & $20 \%$ & $5 \%$ & $69 \%$ & - \\
\hline $2017 / 18$ & 330 & 92 & - & $85 \%$ & $2 \%$ & $14 \%$ & - & - & - & $3 \%$ & $20 \%$ & $5 \%$ & $72 \%$ & - \\
\hline $2018 / 19$ & 330 & 132 & - & $70 \%$ & $9 \%$ & $21 \%$ & - & - & - & $30 \%$ & $3 \%$ & $7 \%$ & $60 \%$ & - \\
\hline \multicolumn{15}{|c|}{ Região: Castro/PR } \\
\hline $2012 / 13$ & 500 & 185 & $2 \%$ & $62 \%$ & $2 \%$ & $20 \%$ & $14 \%$ & - & - & $7 \%$ & $30 \%$ & - & $63 \%$ & - \\
\hline $2013 / 14$ & 460 & 190 & $14 \%$ & $55 \%$ & $3 \%$ & $17 \%$ & $12 \%$ & - & - & $9 \%$ & $33 \%$ & - & $59 \%$ & - \\
\hline $2014 / 15$ & 500 & 150 & $23 \%$ & $42 \%$ & $2 \%$ & $13 \%$ & $20 \%$ & - & - & $5 \%$ & $25 \%$ & - & $70 \%$ & - \\
\hline $2015 / 16$ & 482 & 145 & $25 \%$ & $44 \%$ & $2 \%$ & $8 \%$ & $21 \%$ & - & - & $4 \%$ & $26 \%$ & - & $70 \%$ & - \\
\hline $2016 / 17$ & 500 & 275 & $21 \%$ & $49 \%$ & $2 \%$ & $8 \%$ & $20 \%$ & - & - & $10 \%$ & $35 \%$ & $10 \%$ & $45 \%$ & - \\
\hline $2017 / 18$ & 500 & 200 & $21 \%$ & $49 \%$ & $2 \%$ & $8 \%$ & $20 \%$ & - & - & $10 \%$ & $30 \%$ & - & $60 \%$ & - \\
\hline 2018/19 & 500 & 120 & $14 \%$ & $71 \%$ & $1 \%$ & $9 \%$ & $5 \%$ & - & - & $4 \%$ & $20 \%$ & - & $76 \%$ & - \\
\hline
\end{tabular}

Fonte: CEPEA/CNA (2019).

Notas: ${ }^{1}$ Área de primeira safra ou total é composta pela área cultivável da propriedade - incluindo terra própria e arrendada, não incorporando reserva legal ou outras áreas de mata. ${ }^{2}$ Porcentagens em relação a área total. ${ }^{3}$ Feijão preto e carioca. Células compostas pelo hífen (-) representam o número zero. OGM: organismo geneticamente modificado. NOGM: organismo não geneticamente modificado, ou convencional

Organizações Rurais \& Agroindustriais, Lavras, v. 22, e1554, 2020 
Na Tabela 5 constam informações para duas regiões de Santa Catarina, em anos selecionados. As propriedades típicas deste estado também tiveram estabilidade de área total cultivada ao longo dos anos. Em Campos Novos/SC, na primeira safra prevalece o cultivo de soja de $75 \%$ a $80 \%$ da área de primeira safra, e de $11 \%$ a $20 \%$ de milho, sendo o restante destinado ao feijão. A área de feijão oscilou a cada ano, movimentação relacionada à rentabilidade dada pelo nível de preços. Na segunda safra nesta região, chama atenção o percentual expressivo de área com cobertura verde, ou seja, com culturas não comerciais, em detrimento da redução da área com cultivo de trigo. A aveia branca tem sido adotada em pequena proporção a partir da safra 2017/18.

Em Xanxerê/SC, cultiva-se na primeira safra predominantemente soja ( $85 \%$ da área de primeira safra), e milho (15\%), sendo cultivado feijão apenas nas safras 2015/16 e 2016/17. Na segunda safra, há uma redução no cultivo do trigo nos últimos anos. Como consequência, a área de feijão de inverno (cultivado em segunda safra) tem aumentado nas duas últimas safras, como alternativa ao trigo. A aveia branca foi cultivada na safra 2017/18 visando o mercado de rações, portanto, não houve aplicações de defensivos agrícolas ou fertilizantes, constituindo uma alternativa à aveia preta, além de constituir fonte complementar de receita. Observa-se redução expressiva desta cultura na safra 2018/19, necessitando de um acompanhamento nas safras posteriores a fim de identificar sua viabilidade como cultura alternativa.

Para o Rio Grande do Sul (Tabela 6), dados da região de Carazinho/RS indicam para aumento do tamanho da propriedade típica regional. Na primeira safra na região prevaleceu o cultivo de soja e o cultivo de milho foi inferior a 10\% da área de primeira safra. Já na segunda safra, houve cultivo comercial de trigo em apenas parte da área disponível, que ao longo dos anos está sendo preterida por áreas de cobertura verde.

TABELA 5 - Sistemas produtivos das propriedades típicas do estado de Santa Catarina, entre os anos agrícolas de 2013/14 e 2018/19

\begin{tabular}{|c|c|c|c|c|c|c|c|c|c|c|c|}
\hline \multirow{2}{*}{ Ano-safra } & \multirow{2}{*}{$\begin{array}{l}\text { Área de } 1^{\mathrm{a}} \\
\text { Safra (ha) }{ }^{1}\end{array}$} & \multirow{2}{*}{$\begin{array}{l}\text { Área de } 2^{\mathrm{a}} \\
\text { Safra (ha) }\end{array}$} & \multicolumn{5}{|c|}{ Primeira Safra ${ }^{2}$} & \multicolumn{3}{|c|}{ Segunda Safra Comercial ${ }^{2}$} & \multirow{2}{*}{$\begin{array}{c}\begin{array}{c}\text { Segunda Safra } \\
\text { Cobert. Verde }\end{array} \\
\text { Aveia Preta }\end{array}$} \\
\hline & & & $\begin{array}{c}\text { Soja } \\
\text { NOGM }\end{array}$ & $\begin{array}{l}\text { Soja } \\
\text { OGM }\end{array}$ & $\begin{array}{l}\text { Milho } \\
\text { NOGM }\end{array}$ & $\begin{array}{l}\text { Milho } \\
\text { OGM }\end{array}$ & Feijão $^{3}$ & Feijão $^{3}$ & Trigo & $\begin{array}{l}\text { Aveia } \\
\text { Branca }\end{array}$ & \\
\hline \multicolumn{12}{|c|}{$\begin{array}{l}\text { Região: Campos Novos/ } \\
\text { SC }\end{array}$} \\
\hline 2013/14 & 300 & 40 & - & $70 \%$ & $2 \%$ & $15 \%$ & $13 \%$ & - & $13 \%$ & - & $87 \%$ \\
\hline $2014 / 15$ & 300 & 60 & - & $70 \%$ & $2 \%$ & $18 \%$ & $10 \%$ & - & $20 \%$ & - & $80 \%$ \\
\hline $2015 / 16$ & 300 & 45 & - & $70 \%$ & $1 \%$ & $14 \%$ & $15 \%$ & - & $15 \%$ & - & $85 \%$ \\
\hline $2016 / 17$ & 300 & 30 & - & $80 \%$ & $1 \%$ & $11 \%$ & $8 \%$ & - & $10 \%$ & - & $90 \%$ \\
\hline $2017 / 18$ & 300 & 51 & - & $80 \%$ & $1 \%$ & $10 \%$ & $10 \%$ & - & $7 \%$ & $10 \%$ & $83 \%$ \\
\hline $2018 / 19$ & 320 & 30 & - & $75 \%$ & $7 \%$ & $13 \%$ & $5 \%$ & - & $5 \%$ & $5 \%$ & $91 \%$ \\
\hline \multicolumn{12}{|c|}{ Região: Xanxerê/SC } \\
\hline $2013 / 14$ & 150 & 63 & - & $70 \%$ & - & $30 \%$ & - & - & $42 \%$ & - & $58 \%$ \\
\hline $2014 / 15$ & 150 & 63 & - & $87 \%$ & $1 \%$ & $12 \%$ & - & $7 \%$ & $35 \%$ & - & $58 \%$ \\
\hline $2015 / 16$ & 150 & 45 & - & $67 \%$ & $4 \%$ & $16 \%$ & $13 \%$ & - & $30 \%$ & - & $70 \%$ \\
\hline $2016 / 17$ & 154 & 45 & - & $76 \%$ & - & $20 \%$ & $5 \%$ & - & $29 \%$ & - & $71 \%$ \\
\hline $2017 / 18$ & 150 & 139 & - & $85 \%$ & - & $15 \%$ & - & $8 \%$ & $20 \%$ & $65 \%$ & $7 \%$ \\
\hline $2018 / 19$ & 150 & 105 & - & $85 \%$ & - & $15 \%$ & - & $20 \%$ & $15 \%$ & $35 \%$ & $30 \%$ \\
\hline
\end{tabular}

Fonte: CEPEA/CNA (2019)

Notas: 1 Área de primeira safra ou total é composta pela área cultivável da propriedade - incluindo terra própria e arrendada, não incorporando reserva legal ou outras áreas de mata. 2 Porcentagens em relação a área total. 3 Feijão preto e carioca. Células compostas pelo hífen (-) representam o número zero. OGM: organismo geneticamente modificado. NOGM: organismo não geneticamente modificado, ou convencional 
TABELA 6 - Sistemas produtivos das propriedades típicas do estado do Rio Grande do Sul, entre os anos agrícolas de 2012/13 e 2018/19

\begin{tabular}{|c|c|c|c|c|c|c|c|c|c|}
\hline \multirow{2}{*}{ Ano-safra } & \multirow{2}{*}{$\begin{array}{c}\text { Área de } 1^{\mathrm{a}} \\
\text { Safra } \\
(\mathrm{ha})^{1}\end{array}$} & \multirow{2}{*}{$\begin{array}{l}\text { Área de } 2^{\text {a }} \\
\text { Safra (ha) }\end{array}$} & \multicolumn{3}{|c|}{ Primeira Safra ${ }^{2}$} & \multicolumn{3}{|c|}{ Segunda Safra Comercial ${ }^{2}$} & \multirow{2}{*}{$\begin{array}{c}\begin{array}{c}\text { Segunda Safra } \\
\text { Cobert. Verde }\end{array} \\
\text { Aveia Preta }\end{array}$} \\
\hline & & & $\begin{array}{c}\text { Soja } \\
\text { OGM }\end{array}$ & $\begin{array}{c}\text { Milho } \\
\text { NOGM }\end{array}$ & $\begin{array}{l}\text { Milho } \\
\text { OGM }\end{array}$ & Trigo & Canola & $\begin{array}{l}\text { Aveia } \\
\text { Branca }\end{array}$ & \\
\hline \multicolumn{10}{|c|}{ Região: Carazinho/RS } \\
\hline $2012 / 13$ & 170 & 68 & $94 \%$ & - & $6 \%$ & $40 \%$ & - & - & $60 \%$ \\
\hline $2013 / 14$ & 170 & 40 & $90 \%$ & - & $10 \%$ & $24 \%$ & - & - & $76 \%$ \\
\hline $2014 / 15$ & 170 & 41 & $90 \%$ & - & $10 \%$ & $24 \%$ & - & - & $76 \%$ \\
\hline $2015 / 16$ & 250 & 50 & $95 \%$ & $0,5 \%$ & $5 \%$ & $20 \%$ & - & - & $80 \%$ \\
\hline $2016 / 17$ & 250 & 25 & $90 \%$ & $1 \%$ & $9 \%$ & $10 \%$ & - & - & $90 \%$ \\
\hline $2017 / 18$ & 250 & 20 & $94 \%$ & $1 \%$ & $5 \%$ & $8 \%$ & - & - & $92 \%$ \\
\hline $2018 / 19$ & 250 & 25 & $92 \%$ & $1 \%$ & $7 \%$ & $10 \%$ & - & - & $90 \%$ \\
\hline \multicolumn{10}{|c|}{ Região: Tupanciretã/RS } \\
\hline $2012 / 13$ & 500 & 80 & $100 \%$ & - & - & $16 \%$ & - & - & $84 \%$ \\
\hline $2013 / 14$ & 500 & 120 & $100 \%$ & - & - & $24 \%$ & - & - & $76 \%$ \\
\hline $2014 / 15$ & 500 & 150 & $100 \%$ & - & - & $25 \%$ & $5 \%$ & - & $70 \%$ \\
\hline $2015 / 16$ & 500 & 65 & $100 \%$ & - & - & $13 \%$ & - & - & $87 \%$ \\
\hline $2016 / 17$ & 500 & 50 & $100 \%$ & - & - & $8 \%$ & - & $2 \%$ & $90 \%$ \\
\hline $2017 / 18$ & 500 & 60 & $100 \%$ & - & - & $8 \%$ & - & $4 \%$ & $88 \%$ \\
\hline 2018/19 & 500 & 50 & $100 \%$ & - & - & $6 \%$ & - & $4 \%$ & $90 \%$ \\
\hline
\end{tabular}

Fonte: CEPEA/CNA (2019)

Notas: ${ }^{1}$ Área de primeira safra ou total é composta pela área cultivável da propriedade - incluindo terra própria e arrendada, não incorporando reserva legal ou outras áreas de mata. ${ }^{2}$ Porcentagens em relação a área total. ${ }^{3}$ Feijão preto e carioca. Células compostas pelo hífen (-) representam o número zero. OGM: organismo geneticamente modificado. NOGM: organismo não geneticamente modificado, ou convencional

Na região de Tupanciretã/RS, apenas soja é cultivada na primeira safra. Para a segunda safra, há uso de apenas cerca de $10 \%$ com culturas comerciais, em que também se observa o preterimento do trigo e aumento do cultivo de aveia branca como cultura alternativa. No geral, portanto, se observa que nas regiões dos estados de Santa Catarina e Rio Grande do Sul prevalece o cultivo de soja na primeira safra, enquanto na segunda safra o solo acaba sendo dedicado em maior parte por lavouras de cobertura verde, ou seja, os produtores parecem não encontrar atratividade no cultivo de lavouras com finalidades comerciais especialmente no período chamado de inverno.

\section{CONSIDERAÇÕES FINAIS}

Este estudo teve por objetivo caracterizar a dinâmica produtiva dos cultivos de grãos e da propriedade típica regional no Sul do Brasil, entre as safras 2012/13 e 2018/19. Para tanto, foram utilizadas fontes públicas de informação, e dados coletados e disponibilizados pelo Cepea/CNA (2019) sobre a propriedade típica regional.

Ao se observar o padrão de cultivo de culturas temporárias no Sul do Brasil (IBGE, 2018), bem com o balanço de oferta e demanda nacional (CONAB, 2021a), foram identificadas tendências regionais entre as safras analisadas. Ao se tratar de sistemas produtivos com base nos dados do Cepea/CNA (2019), nota-se que os padrões identificados nas fontes públicas de informação são condizentes com a realidade, para todas as regiões analisadas.

Em primeira safra, predomina-se o cultivo de soja em todas as regiões, sendo que para algumas delas há uma menor proporção do cultivo de milho. Em segunda safra, há uma nítida tendência de redução do cultivo de trigo para os anos analisados e, por consequente, uma busca por culturas alternativas. A cobertura verde em segunda safra tem representado elevada proporção de área na maioria das regiões. 
Não obstante, futuras pesquisas são necessárias para quantificar a superioridade da cultura da soja em termos econômicos, dada sua crescente participação nas propriedades típicas regionais do Sul do Brasil. Ainda, deve-se compreender a preferência pela adoção de cobertura verde na segunda safra, em detrimento do trigo, haja vista que não é comercializada e, por conseguinte, não gera receita.

Este estudo contribui para identificar os sistemas produtivos predominantes no Sul do Brasil, bem como o tamanho modal das propriedades típicas regionais, possibilitando diversas aplicações tanto no âmbito público, para formação de políticas públicas, quanto no privado, para alinhamento de estratégias das organizações. A partir do exposto, pode-se inferir sobre a escolha do produtor sobre as culturas e tecnologias adotadas ao longo do tempo, proporcionando inclusive indícios sobre as decisões nos próximos anos.

Este estudo tem como limitador o fato de que não foi possível avaliar as justificativas e impactos econômicos das decisões do produtor quanto à preferência de cultivo de soja na primeira safra e de deixar parte expressiva da área em segunda safra sem um cultivo comercial. Assim, como estudo futuro entende-se importante a quantificação e análises das relações de risco e taxa de retorno de culturas e sistemas produtivos de grãos, para buscar mensurar as relações com as decisões dos produtores.

\section{AGRADECIMENTOS}

Os autores agradecem ao Centro de Estudos Avançados em Economia Aplicada (Cepea), da Escola Superior de Agricultura "Luiz de Queiroz", Universidade de São Paulo (Esalq-USP), pela coleta e disponibilização dos dados, e à Coordenação de Aperfeiçoamento de Pessoal de Nível Superior (Capes) pela bolsa de estudos concedida no período de realização da pesquisa.

\section{REFERÊNCIAS}

BAUMGRATZ, E. I.; MERA, C. M. P. de; FIORIN, J. E.; CASTRO, N. L. M. de; CASTRO, R. de. Produção de trigo. A decisão por análise econômico-financeira ${ }^{1}$. Revista de Política Agrícola, v. 26, n. 3, p. 8-21, 2017.

BRUM, A. L.; MULLER, P. K. A realidade da cadeia do trigo no Brasil : o elo produtores/cooperativas. Revista de Economia e Sociologia Rural, v. 46, n. 1, p. 145-169, 2008 .
BULLOCK, D. G. Crop rotation. Critical Reviews in Plant Sciences, v. 11, n. 4, p. 309-326, 1992.

CEPEA/CNA - Centro de Estudos Avançados em Economia Aplicada / Confederação da Agricultura e Pecuária do Brasil. Projeto Campo Futuro. 2019.

CHIBANDA, C.; AGETHEN, K.; DEBlitZ, C.; ZIMMER, Y.; ALMADANI, M. I.; GARMING, H.; LASNER, T. The typical farm approach and its application by the agri benchmark network. Agriculture, v. 10, n. 12, p. $646,2020$.

CONAB - Companhia Nacional de Abastecimento. Quadro de Oferta e Demanda. Disponível em: $<$ https://portaldeinformacoes.conab.gov.br/index. php/oferta?view=default $>$. Acesso em: 30 mar. 2021. $2021 \mathrm{a}$.

CONAB - Companhia Nacional de Abastecimento. Série Histórica das Safras. Disponível em: $<$ https://www. conab.gov.br/info-agro/safras/serie-historica-das-safras>. Acesso em: 30 mar. 2021. 2021b.

DEBLITZ, C.; ISERMEYER, F.; ANDERSON, D.; HEMME, T.; KNUTSON, R. The International Farm Comparison Network (IFCN): Objectives, Organisation, First Results on Dairy Production. IFC, Washington, DC, USA, 1998.

DEBIASI, H.; LEVIEN, R.; TREIN, C. R.; CONTE, O.; KAMIMURA, K. M. Produtividade de soja e milho após coberturas de inverno e descompactação mecânica do solo. Pesquisa Agropecuaria Brasileira, v. 45, n. 6, p. 603-612, 2010.

DIJK, M. van; MORLEY, T.; JONGENEEL, R.; ITTERSUM, M. van; REIDSMA, P.; RUBEN, R. Disentangling agronomic and economic yield gaps: An integrated framework and application. Agricultural Systems, v. 154, p. 90-99, 2017.

ELLIOTT, F. F. The "Representative Firm" Idea Applied to Research and Extension in Agricultural Economics. Journal of Farm Economics, v. 10, n. 4, p. 483-498, 1928.

EMYGDIO, B. M.; ROSA, A. P. S. A. de; OLIVEIRA, A. C. B. de. Cultivo de soja e milho em terras baixas do Rio Grande do Sul. Embrapa: 2017. 
FEUZ, D. M.; SKOLD, M. D. Typical Farm Theory in Agricultural Research. Journal of Sustainable Agriculture, v. 2, n. 2, p. 43-58, 1991.

FONTE, C. T.; GALON, L.; BEUTLER, A. N.; PERIN, G. F.; PAULETTI, E. S. S.; BASSO, F. J. M.; HOLZ, C. M.; SANTIN, C. O. Coberturas vegetais do solo e manejo de cultivo e suas contribuições para as culturas agrícolas. Revista Brasileira de Ciências Agrárias, v. 13, n. 1, e. 5501, 2018.

FRANCHINI, J. C.; DEBIASI, H.; BALBINOT JUNIOR, A. A.; TONON, B. C.; FARIAS, J. R. B.; OLIVEIRA, M. C. N. de; TORRES, E. Evolution of crop yields in different tillage and cropping systems over two decades in southern Brazil. Field Crops Research, v. 137, p. 178-185, 2012.

IBARROLA-RIVAS, M. J.; NONHEBEL, S. Variations in the use of resources for food: Land, nitrogen fertilizer and food nexus. Sustainability, v. 8, n. 12, p. 1322, 2016.

IBGE - Instituto Brasileiro de Geografia e Estatística. Censo Agropecuário. Disponível em: $<$ https:// censos.ibge.gov.br/agro/2017/>. Acesso em: 14 jan. 2020. 2017.

IBGE - Instituto Brasileiro de Geografia e Estatística. Produção Agrícola Municipal. Disponível em: $<$ https:// sidra.ibge.gov.br/pesquisa/pam/tabelas $>$. Acesso em: 14 jan. 2020. 2018.

JONES, J. W.; ANTLE, J. M.; BASSO, B.; BOOTE, K. J.; CONANT, R. T.; FOSTER, I.; WHEELER, T. R. Brief history of agricultural systems modeling. Agricultural Systems, v. 155, p. 240-254, 2016.
KAY, R. D.; EDWARDS, W. M.; DUFFY, P. A. Gestão de Propriedades Rurais. AMGH: 2014.

KING, A. E.; HOFMOCKEL, K. S. Diversified cropping systems support greater microbial cycling and retention of carbon and nitrogen. Agriculture, Ecosystems and Environment, v. 240, p. 66-76, 2017.

OLIVEIRA NETO, A. A. de. A produtividade da soja: análise e perspectivas. Compêndio de estudos da Conab, v. 10, 2017. Disponível em <https://www.conab. gov.br/uploads/arquivos/17_08_02_14_27_28_10_ compendio_de_estudos_conab_a_produtividade_da soja_-_analise_e_perspectivas_-_volume_10_2017.pdf $>$. Acesso em: 22 mai. 2021. 2017.

OSAKI, M.; ALVES, L. R. A.; LIMA, F. F.; RIBEIRO, R. G.; BARROS, G. S. de C. Risks associated with a doublecropping production system - a case study in southern Brazil. Scientia Agricola, v. 76, n. 2, p. 130-138, 2019.

POWER, J. F. Legumes and crop rotations. In. FRANCIS, C. A.; FLORA, C. B.; KINGS, L. D. (Org.). Sustainable agriculture in Temperate Zones. Wiley, New York. p.178-187, 1990.

ST-MARTIN, A.; VICO, G.; BERGKVIST, G.; BOMMARCO, R. Diverse cropping systems enhanced yield but did not improve yield stability in a 52-year long experiment. Agriculture, Ecosystems and Environment, v. 247, p. 337-342, 2017.

TANAKA, D. L.; KRUPINSKY, J. M.; LIEBIG, M. A.; MERRILL, S. D.; RIES, R. E.; HENDRICKSON, J. R.; HANSON, J. D. Dynamic Cropping Systems: An adaptable approach to crop productionin the Great Plains. Agronomy Journal, v. 94, n. 5, p. 957-961, 2002. 